Da Rocha, C.G., Tezel, A., Talebi, S., and Koskela, L. (2018). "Product Modularity, Tolerance Management, and Visual Management: Potential synergies." In: Proc. $26^{\text {th }}$ Annual Conference of the International. Group for Lean Construction (IGLC), González, V.A. (ed.), Chennai, India, pp. 582-592. DOI: doi.org/10.24928/2018/0482. Available at: www.iglc.net.

\title{
PRODUCT MODULARITY, TOLERANCE MANAGEMENT, AND VISUAL MANAGEMENT: POTENTIAL SYNERGIES
}

\author{
Cecilia Gravina da Rocha ${ }^{1}$, Algan Tezel ${ }^{2}$, Saeed Talebi ${ }^{3}$, and Lauri Koskela ${ }^{4}$
}

\begin{abstract}
Product Modularity refers to the hierarchical partitioning of products into their constitutive components. This concept has been explored in manufacturing to ease product design, simplify production, and to efficiently provide variety. Efforts have been made to transfer this knowledge to the construction context (i.e. one-off products, temporary supply chain, production taking place inside the product), especially to support the latter goal: variety. Yet, it is argued that a re-conceptualization of building design and production is required for the successful application of modularization. That is, materials and components used to erect a building should be grouped (at least conceptually) as families of modules and work (production tasks) has to be structured according to such organization. This paper explores the synergies among Product Modularity, Tolerance Management, and Visual Management to improve and ease the understanding of such reconceptualization in design and production. It also examines patterns from the theoretical background of Design for Behaviour Change, and how these can be adapted to embed information in modules and present tolerance data in design drawings.
\end{abstract}

\section{KEYWORDS}

Work package, poka-yoke, Product Modularity, Tolerance Management, Visual Management, and Design for Behaviour Change.

1 Assistant Professor, Postgraduate Program in Civil Engineering (PPGEC), Federal Univ. of Rio Grande do Sul (UFRGS), 99 Osvaldo Aranha Av., 3rd Floor, CEP 90035-190, Porto Alegre, RS, Brazil. cecilia.rocha@ufrgs.br

2 Lecturer, School of Art, Design and Architecture, University of Huddersfield, Queen Street Building, Queen St, Huddersfield, West Yorkshire, HD1 3DU, United Kingdom. A.Tezel@ hud.ac.uk

3 PhD Candidate, School of Art, Design and Architecture, University of Huddersfield, Queen Street Building, Queen St, Huddersfield, West Yorkshire, HD1 3DU, United Kingdom. Saeed.Talebi@hud.ac.uk

4 Professor, School of Art, Design and Architecture, University of Huddersfield, Queen Street Building, Queen St, Huddersfield, West Yorkshire, HD1 3DU, United Kingdom. L.Koskela@hud.ac.uk 


\section{INTRODUCTION}

Product Modularity is concerned with the partitioning (or hierarchical breakdown) of a product into its constitutive modules (or chunks), namely, a set of one or more physical parts. Modular architectures involve a one-to-one correspondence between functional elements and physical parts comprising each module (Ulrich 1995). The interfaces are loosely coupled (e.g. Sanchez and Mahoney 1996, Hofman et al. 2009), which implies that modules can be mixed and matched to create distinct product variants. Bus, sectional, and slot are some modular architecture types (Pine 1999; Ulrich 1995; Fixson 2005), which vary in terms of interface types among connecting modules. In a bus architecture, each family of modules, a set of modules that provide distinct levels for a given requirement (Salvador et al. 2002), is connected to the main module (bus) via a different interface (Ulrich 1995). Alternatively, in a sectional architecture, all modules are connected via a single interface type (Ulrich 1995).

Modular architectures can be adopted for a number of reasons such as to ease design and simplify production (Sako and Murray 1999; Baldwin and Clark 2003). Product Modularity has also been proposed as a key strategy to provide product variety (or customization) with efficiencies similar to mass production (Pine 1993; Da Silveira et al. 2001; Piller and Kumar 2006) and to minimize disruptions in the construction flow (e.g. da Rocha and Kemmer 2013; 2015). This requires a building and its constitutive components and/or materials to be conceived as modules from design and process viewpoints (Da Rocha and Kemmer 2018). Indeed, a brick can be considered a module, as proposed by Gosling et al. (2016), by directly applying the hierarchical breakdown rationale. Yet, this provides limited benefits despite the fact that bricks are highly modular: they are all connected via the same interface type (mortar) and can create an infinite amount of combinations (Da Rocha and Kemmer 2018). Production benefits are created when small parts such as bricks are grouped into large chunks (or modules).

Such aggregation can be (i) only conceptual or (ii) conceptual and physical. The former refers to traditional construction and requires buildings to be conceived as families of design modules and work to be structured with a one-to-one correspondence with each family (Da Rocha and Kemmer 2018). The latter refers to pre-fabrication, where building parts are added together off-site creating stable sub-assemblies, which are only assembled on site. Japanese houses comprised of volumetric pods produced in factories (Linner and Bock 2012), and pre-fabricated industrial structures and prison building spaces (Falmer 2016; Evans and Johnston 2017) are prime examples. In either case, buildings need to be re-conceptualized from design and process viewpoints (Da Rocha and Kemmer 2018). Buildings should not be designed as an unconceivable large number of small parts (where many parts actually change depending on the customisation requirements) but rather as a manageable set of large chunks that can be mixed and matched to meet all the customisation requirements. In addition, work should be structured so that work packages will deliver the modules (a set of buildings parts) rather than some indistinctive combinations of small parts (Da Rocha and Kemmer 2018). 
There are several challenges involved in bringing this re-conceptualization to practice. Two of these can be summarized as follows: (i) How to communicate this new understanding of buildings (as a set of modules) within and across design and production? and (ii) How to ensure an appropriate connection among modules in design and production?. This paper seeks to address these inter-related research questions by reviewing and examining Tolerance Management and Visual Management and their conceptual underpinnings. Based on this analysis, the synergies among these topics are discussed and suggestions to further advance in the theoretical understanding and practical application of Product Modularity in construction are presented.

\section{LITERATURE REVIEW}

\section{VISUAL MANAGEMENT}

Visual Management (VM) is a close range communication management strategy that relies on the effectiveness of sensory stimuli; visual (Figure 1), auditory, tactile, olfactory, and gustatory) to facilitate smooth and efficient production (Tezel et al. 2015, 2016). VM systems are often divided into four: (i) visual indicators that only convey information, (ii) visual signals that grab attention, (iii) visual controls that limit human action by imposing some constraints and (iv) visual guarantees (poka-yokes) that guarantee the correct outcome by either warning of or preventing human error (Galsworth 2005).
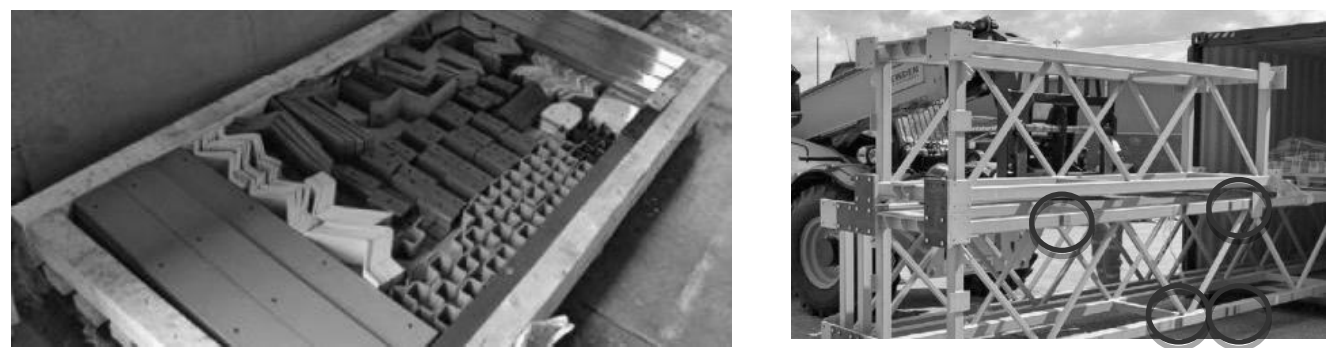

Figure 1: A crate of colored brackets and fixing connections of the off-site components of an industrial plant, which match to the colored stickers positioned on the structural components (circled above) during the construction process (Falmer 2016).

Poka-yokes are often used as complementary systems alongside statistical quality control in manufacturing to achieve quality at source and the zero defect ideal in production (Vinod et al. 2015). They have been classified as symbolic, functional, and physical (Saurin et al. 2012). In the latter case (physical poka-yokes), the contact surfaces of two modules are deliberately designed to allow only the correct assembly of modules (Shimbun 1988).

In a slot architecture, the distinct interfaces design avoids incorrect assemblies. Differently, a sectional architecture does not guaranty a correct assembly as all modules are connected via the same interface type. In the latter case, additional information (besides the geometry of interfaces) can be adopted to enable (albeit not guarantee) only the appropriate combination among modules. This includes coding structures like patterns; distinctive textures on the handles or human contact points of the module elements for 
tactile coding, colour-coded system (Figure 1), and basic alpha-numeric characters or symbols.

\section{TOLERANCE MANAGEMENT}

There is no consensus about what Tolerance Management (TM) exactly is and what it consists of. According to Milberg (2006), TM is about utilising various tools and methods in order to (i) attain the highest conceivable quality and performance to deliver the maximum value and (ii) to avoid any interruption of flow due to tolerance-related problems to minimize the waste. TM includes planning to achieve the required accuracy, incorporate tolerances in design, and control whether tolerance requirements have been obtained. Tolerance problems can be defined as when two or more modules are connected tolerance-wise but either they do not satisfy functional requirements or there is a fit-up problem with them due to exceeded permissible variations.

Conventionally, tolerance risks are often mitigated by specifying stringent tolerances for in situ parts (Milberg 2006), manufacturing products with tighter tolerances (Gibb 1999), and gaining better control of tolerances on site (Landin 2010). Yet, two main parameters can lead to problems. First, tolerance can range from less than a millimetre for off-site made parts to several millimetres for in situ parts (Ballast 2007). Second, the dynamic loads applied during transport and lifts of modules produced off site (Lawson et al. 2014), and structural movements due to different types of loads (Alexander 2014) can result in tolerance problems in the interface between parts.

Geometric Dimensioning and Tolerancing (GD\&T) is a symbolic language that specifies the permitted variation in form, orientation, profile and location of features on a module and represents the relationship between features in an assembly. Feature in this context refers to either the size or the surface of a module (Krulikowski 2012). Milberg and Tommelein (2005) propose a method called tolerance mapping which combines the GD\&T principles and graph theory to describe design intent regarding tolerances. Talebi et al. (submitted) took the idea further and propose a system for tolerance specification termed Geometric Dimensioning and Tolerancing in Construction (GD\&TIC). GD\&TIC groups the geometric variations of a feature into four categories, geometric characteristics and symbols (Table 2). Figure 2a shows the maximum permissible variations in size and geometry of two modules. Figure $2 \mathrm{~b}$ shows how the tolerance requirements on the modules and between them can be specified using GD\&TIC. 

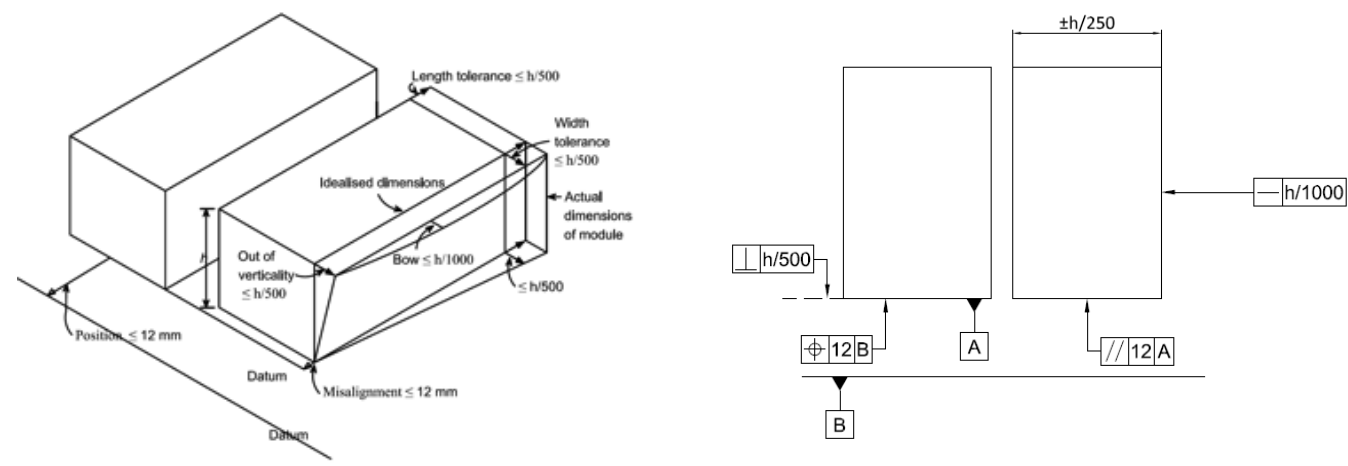

Figure 2: (a) The maximum permissible variations in geometry of a two modules (adapted from Lawson et al. 2014), and (b) application of GD\&TIC for the modules

Table 1: Geometric Characteristic Symbols in GD\&TIC (Talebi et al. 2018)

\begin{tabular}{lll}
\hline Type of Tolerance & Geometric Characteristics & Symbol \\
\hline $\begin{array}{l}\text { Form: establishes the shape of a } \\
\text { surface. }\end{array}$ & $\begin{array}{l}\text { Straightness: it represents how straight a surface is on } \\
\text { a feature along a line }\end{array}$ \\
\cline { 2 - 3 } & $\begin{array}{l}\text { Flatness: it demonstrates the amount of deviation of } \\
\text { flatness that a surface is allowed to have }\end{array}$ \\
\hline $\begin{array}{l}\text { Profile: is the outline of a part } \\
\text { feature and the True Profile is the } \\
\text { exact profile of part feature. }\end{array}$ & $\begin{array}{l}\text { Flatness: it demonstrates the amount of deviation of } \\
\text { flatness that a surface is allowed to have }\end{array}$ \\
\hline $\begin{array}{l}\text { Orientation: describes the } \\
\text { relationship between features and } \\
\text { datums at particular angles. }\end{array}$ & $\begin{array}{l}\text { Perpendicularity: It is a condition used to ensure that a } \\
\text { surface centreplane, or axis is exactly at a right angle } \\
\text { relative to a reference plane or axis. }\end{array}$ \\
\cline { 2 - 3 } & $\begin{array}{l}\text { Parallelism: it limits the amount of variation allowed } \\
\text { over an entire plane, from being parallel to the } \\
\text { reference plane }\end{array}$ \\
\hline $\begin{array}{l}\text { Location: establishes the position } \\
\text { of the feature relative to a datum. }\end{array}$ & $\begin{array}{l}\text { Position: It is the location tolerance of a feature } \\
\text { relative to its nominal position }\end{array}$ \\
\hline
\end{tabular}

\section{RESEARCH METHOD}

The research method adopted here involved three steps. First, the fundamental conceptual underpinnings of each area examined (Product Modularity, Tolerance Management, and Visual Management) were identified and understood. Second, the synergies among these underpinnings were established and graphically illustrated in Figure 3, which is inspired by the time, space, and information diagram for real manufacturing cells proposed by Hyer and Brown (1999). Thirdly, the Design for Behaviour Change literature was reviewed to identify design patterns to embed information either (i) in blueprints, 3D or BIM models or (ii) in module design to bring the identified synergies to a next level, which is detailed in Conclusions.

\section{RESULTS}

\section{SYNERGIES ENCOUNTERED}

VM provides a number of tools to improve the communication within and across design and production regarding (Figure 3): (i) what are the modules and (ii) what modules are 
connected/combined to create the product variants to meet various customisation requirements. The double arrows in Figure 1 show the iteration between (i) VM and PM and (ii) VM and TM. Namely, once modules and their combinations become clear by using visual tools, these can be re-defined, similarly to the problem-solution process in design (Dorst and Cross 2001).

Differently, a two-way connection is established between PM and TM. PM provides inputs to TM: it outlines the modules that are combined, which from a tolerance viewpoint defines critical connections to be managed. This is relevant not only for buildings comprised solely of large volumetric pods assembled on site but also buildings erected by fabricating and/or assembling small building parts (pipes, bricks, cladding, rebar, sink, etc) on site.

Complementarily, TM provides an input to PM: it clarifies the technicalities to be considered in the connection between every two modules by using GD\&TIC. In PM, such connection is addressed under the interface notion and the terms loosely coupled (e.g. Sanchez and Mahoney 1996, Hofman et al. 2009) or decoupled (e.g. Ulrich 1995; Doran and Giannakis 2011) are often used. Yet, these are vague, providing limited understanding for its application in construction. Namely, it is not clear how such terms translate into building design and production requirements.

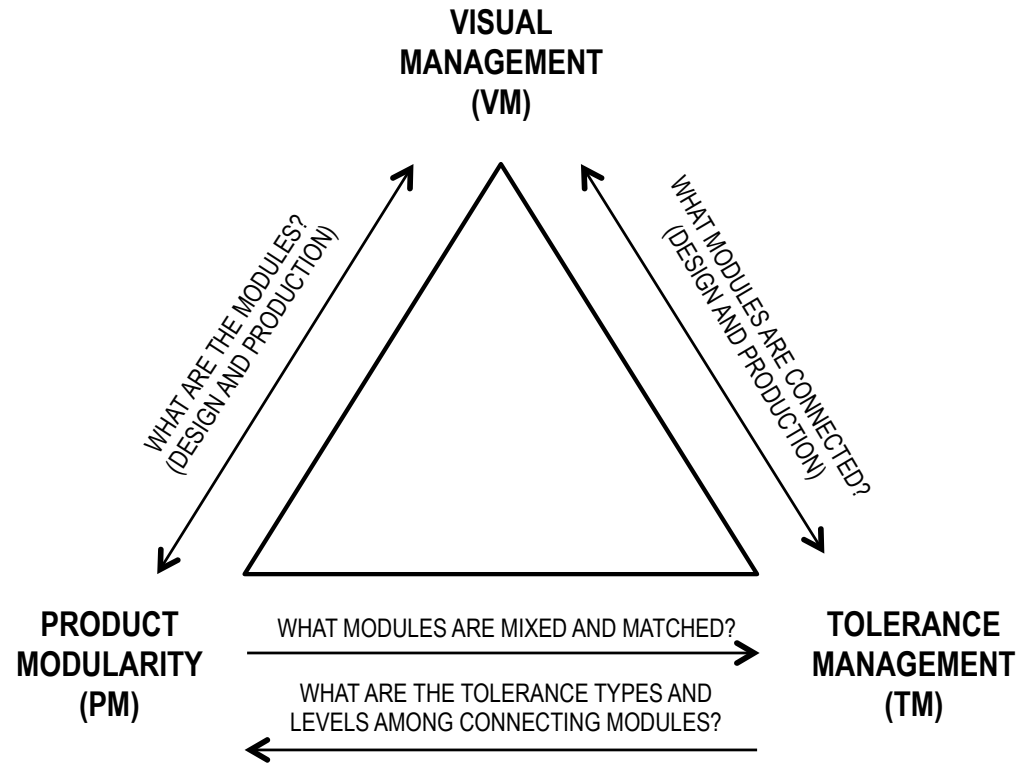

Figure 3: Synergies among Product Modularity, Visual Management, and Tolerance Management

\section{EMBEDDING INFORMATION IN PRODUCT DESIGN}

VM aims to create a visual workplace, in which process transparency, the communication ability of process elements, is maintained at a high level (Greif, 1991). In many cases, information is externally presented, particularly, by adding tools such as shadow boards, information boards, A3s, graphs, charts, sketches, mascots, signs, sticky charts, and 
decisions trees. It can be internally conveyed by embedding information in the product design (e.g. contact type poka-yoke devices such as the elevator not moving unless doors are closed). However, there are in-between instances, where information is not externally provided but is neither completely embedded in the product.

Considering the potential to embed information in product design (more specifically here in modules design), Design for Behaviour Change (e.g. Lockton 2015; Lockton et al. 2010; Daae and Boks 2014; Tromp et al. 2011) including specific application such as Design for Sustainable Behaviour (DfSB) (e.g. Lilley 2009; Wever et al. 2008), can provide important insights. Lockton (2015) devised the Design with Intent (DwI) toolkit: a deck of cards comprised of more than a hundred design patterns (organized in six groups) to support behaviour change via product design. For the synergies considered here, twelve patterns proposed by Lockton (2015) are particularly applicable and can be adapted as follows: (i) colour association (use colour to indicate association among elements); (ii) proximity and grouping (group elements to indicate similarity or joint usage); (iii) similarity (make elements look similar to indicate they share characteristics); (iv) (a)symmetry (use symmetry to make elements look related and asymmetry to show difference); (v) implied sequence (organize elements to indicate the sequence to be followed); (vi) possibility trees (provide a " map" of routes or choice that can be made to achieve different goals); (vii) matched affordances (design modules and interfaces so they fit together only in the right way); (viii) interlocks (design modules and interfaces to be combined only in the right way or sequence); (ix) task lock-in/out (design modules and interfaces to support only the correct assembly); (x) feedback through form (design modules and interfaces to give feedback or suggest cues for assembly); (xi) prominence (exaggerate or make more obvious features of modules and interfaces that require attention); and (xii) perceived affordances (design modules and interfaces to suggest or constraint inappropriate assembly).

\section{CONCLUSIONS}

This paper examined the synergies among Tolerance Management, Visual Management, and Product Modularity, particularly for the latter concept to be successfully applied in construction. VM can support the definition of modular architectures during design (i.e. what are the physical chunks comprising each module? what modules are mixed and matched?) by using tools (e.g. A3s, information boards, etc) to ease the visualization and understanding of modules and their combinations. Once the architecture has been defined, VM can ensure only correct combinations (or assembly of modules) are made during production.

TM sheds some light on an ill-defined albeit important conceptual underpinning of Product Modularity: the interfaces among modules that are combined. By understanding tolerance types (form, profile, orientation, and location), the technicalities of combining every two modules (particularly when one is produced on site and the other off site) become clear. Here, VM can ease the communication of tolerance requirements both in design (determining the tolerance types and requirements for the interface between every 
two modules) and production (ensuring that the modules combined meet the defined requirements).

Lastly, (i) embedding information in product design versus (ii) adding external elements (e.g. signs, notices, charts, etc) to present such information are important notions that emerged. The former is exemplified by poka-yokes, in which information is not presented by a third element (e.g. a sign saying "Buck your seat belt prior driving") but embedded in the product design (e.g. a car which one can only start driving once the seat belt is buckled). Information embedding, as already extensively reported in the pokayoke and VM literature (Galsworth, 2005; Saurin et al. 2012; Tezel et al. 2015), is a means to ensure that only the desire action or behaviour happens. This can be directly translated and applied to module assembly in production to ensure (i) only the correct/allowed combinations among modules are performed and (ii) that the combination (or interface) of every two modules meets the defined tolerance requirements.

Yet, embedding information (rather than adding third elements) can also be viewed as a means to ease communication and to reduce cognitive effort. For example, embedding tolerance information in the already existing elements (slabs, beams, doors, walls, etc) presented in blueprints, 3D or BIM models rather than adding extra elements such as the symbols for tolerance types (Table 1). Whether and how this can be done remain to be investigated. The design patterns reviewed and adapted to construction (previous section) provide a starting point. For example, the application of the colour association pattern could lead to a colour-coding system to identify tolerance types, potentially leading to less cognitive effort than learning a new symbology (Table 1).

As for the two questions presented in the introduction, the following conclusions can be drawn. VM tools support a visual understanding of what are modules, easing the communication within and across design and production. TM clarifies the technicalities involved in the connection between every two modules (modules interface) in design, and also sets requirements to be considered in production. Such information (involved in design and production stages) can be (i) embedded in blue prints, 3D or BIM models, or in the modules themselves, or (ii) presented by external elements.

\section{ACKNOWLEDGMENTS}

Dr. da Rocha acknowledges the financial support by National Council for Scientific and Technological Development (CNPq).

\section{REFERENCES}

Alexander, S. (2014). Design for movement in buildings, CIRIA, London.

Baldwin, C. Y., and Clark, K. B. (2003). "Managing in an age of modularity." Managing in the modular age: Architectures, networks, and organizations, 149, 84-93.

Ballast, D. K. (2007). Handbook of construction tolerances, John Wiley \& Sons, Inc., New Jersey.

da Rocha, C. G., and Kemmer, S. L. (2013). "Method to Implement Delayed Product Differentiation in Construction of High-Rise Apartment Building Projects." Journal of Construction Engineering and Management, 139(10), 5013001. 
da Rocha, C. G., and Kemmer, S. L. (2015). "Closure to 'Method to Implement Delayed Product Differentiation in Construction of High-Rise Apartment Building Projects' by Cecília Gravina da Rocha and Sergio Luiz Kemmer.” Journal of Construction Engineering and Management, 141(2), 7014004.

da Rocha, C.G. and Kemmer, S. (2018) "Integrating product modularity and work structuring in construction". Construction Management and Economics, DOI: 10.1080/01446193.2018.1464198

Da Silveira, G., Borenstein, D., and Fogliatto, F. S. (2001). "Mass customization: Literature review and research directions." International Journal of Production Economics, 72(1), 113.

Daae, J. Z., and Boks, C. (2014). "Dimensions of behaviour change.” J. of Design Research, $12(3), 145$.

Doran, D., and Giannakis, M. (2011). "An examination of a modular supply chain: a construction sector perspective.” Supply Chain Management: An International Journal, 16(4), 260-270.

Dorst, K., and Cross, N. (2001). "Creativity in the design process: co-evolution of problemsolution." Design Studies, 22(5), 425-437.

Evans, A., and Johnston, J. (2017). "A New Model for Delivery of Assets in the Public Sector", LCI-UK 2017 Yearly Summit Keynote Presentation. Available at: https://leanconstruction.org.uk/conferences/lci-summit-2017/

Farmer, M. (2016). Modernise or Die: Time to Decide the Industry's Future. Construction Leadership Council. <http://www.constructionleadershipcouncil.co.uk/wpcontent/uploads/2016/10/Farmer-Review.pdf $>$ (Feb 11, 2018).

Fixson, S. K. (2005). "Product architecture assessment: a tool to link product, process, and supply chain design decisions." Journal of Operations Management, 23(3-4), 345-369.

Galsworth, G. D. (2005). Visual Workplace: Visual Thinking, Enterprise Press, Portland, USA.

Gibb, A. G. (2001). "Standardization and pre-assembly distinguishing myth from reality using case study research." Construction Management \& Economics, 19(3), 307-315.

Gosling, J., Pero, M., Schoenwitz, M., Towill, D., and Cigolini, R. (2016). "Defining and Categorizing Modules in Building Projects: An International Perspective." Journal of Construction Engineering and Management, 142(11), 4016062.

Greif, M. (1991). The Visual Factory: Building Participation through Shared Information, CRC Press, Cambridge.

Hofman, E., Voordijk, H., and Halman, J. (2009). "Matching supply networks to a modular product architecture in the house-building industry." Building Research \& Information, 37(1), 31-42.

Hyer, N., and Brown, K. (1999). "The discipline of real cells.” Journal of Operations Management, 17(5), 557-574.

Krulikowski, A. (2012). Fundamentals of Geometric Dimensioning and Tolerancing, Cengage Learning, New York.

Landin, A. (2010). "Demands on the tolerances when industrialising the construction sector." New Perspective in Industrialisation in Construction, 197-205.

Lawson, M., Ogden, R., and Goodier, C. (2014). Design in modular construction, CRC Press, Boca Raton, FL. 
Lilley, D. (2009). “Design for sustainable behaviour: strategies and perceptions.” Design Studies, 30(6), 704-720.

Linner, T., and Bock, T. (2012). "Evolution of large-scale industrialisation and service innovation in Japanese prefabrication industry." Construction Innovation, 12(2), 156-178.

Lockton, D. (2015). Design with Intent: Insights, methods and patterns for designing with people, behaviour and understanding. Available on http://designwithintent.co.uk/

Lockton, D., Harrison, D., and Stanton, N. A. (2010). "The Design with Intent Method: A design tool for influencing user behaviour.” Applied Ergonomics, 41(3), 382-392.

Milberg, C. (2006). "Application of tolerance management to civil systems" (Doctoral thesis). University of California, Berkeley.

Piller, F., and Kumar, A. (2006). "For each, their own: The strategic imperative of mass customization." Industrial Engineer, 38(9).

Pimmler, T. U., and Eppinger, S. D. (1994). "Integration analysis of product decompositions." Proceedings of the ASME Conference on Design Theory and Methodology, Minneapolis, 341-351.

Pine, B. J. (1993). "Making mass customization happen: Strategies for the new competitive realities." Planning Review, 21(5), 23-24.

Pine, B. J. (1999). Mass customization: the new frontier in business competition. Harvard Business School Press, Boston, Mass.

Rocha, C., Formoso, C., and Tzortzopoulos, P. (2015). "Adopting Product Modularity in House Building to Support Mass Customisation.” Sustainability, 7(5), 4919-4937.

Sako, M., and Murray, F. (1999). "Modules in design, production, and use: Implications for the global automobile industry." MIT IMVP Annual Sponsors Meeting, Cambridge.

Sanchez, R., and Mahoney, J. (1996). "Modularity, Flexibility, and Knowledge Management in Product and Organization Design." Strategic Management Journal, 17, 63-76.

Saurin, T. A., Ribeiro, J. L. D., and Vidor, G. (2012). "A Framework for Assessing PokaYoke Devices." Journal of Manufacturing Systems, 31(3), 358-366.

Shimbun, N. (1988). Poka-Yoke: Improving Product Quality by Preventing Defects, Productivity Press, Portland, USA.

Talebi, S., Koskela, L., Shelbourn, M., and Tzortzopoulos, P. (2016). "Critical review of tolerance management in construction." 24th Annual Conference of the International Group for Lean Construction, IGLC, Boston, USA, 63-72.

Talebi, S., Koskela, L., Tzortzopoulos, P., Krulikowski, A., \&Tommelein, I. (submitted). Fundamentals of Geometric Dimensioning and Tolerancing in Construction (GD\&TIC). Manuscript submitted for publication.

Tezel, A., Koskela, L., and Tzortzopoulos, P. (2016). "Visual Management in Production Management: A Literature Synthesis.” Journal of Manufacturing Technology Management, 27(6), 766-799.

Tezel, A., Koskela, L., Tzortzopoulos, P., Formoso, C. T.,and Alves, T. (2015). "Visual Management in Brazilian Construction Companies: Taxonomy and Guidelines for Implementation.” Journal of Management in Engineering, 31(6), 05015001.

Tromp, N., Hekkert, P., and Verbeek, P.P. (2011). "Design for Socially Responsible Behavior: A Classification of Influence Based on Intended User Experience.” Design Issues, 27(3), 3-19.

Ulrich, K. (1995). "The role of product architecture in the manufacturing firm." Research Policy, 24(3), 419-440. 
Vinod, M., Devadasan, S. R., Sunil, D. T., and Thilak, V. M. M. (2015). "Six Sigma through Poka-Yoke: A Navigation through Literature Arena." The International Journal of Advanced Manufacturing Technology, 81(1-4), 315-327.

Wever, R., van Kuijk, J., and Boks, C. (2008). "User-centred design for sustainable behaviour.” International Journal of Sustainable Engineering, 1(1), 9-20. 